\title{
Pericarditis por SARS-CoV-2: informe de caso
}

\author{
SARS-COV-2 pericarditis: Case report
}

\author{
Andrea Tufo-Pereyra, Cristhian E. Scatularo*, Federico Cardone y Hugo Grancelli \\ Departamento de Cardiología, Sanatorio de la Trinidad de Palermo. Buenos Aires, Argentina
}

La enfermedad por coronavirus 2019 (COVID-19) es una enfermedad infectocontagiosa causada por el SARS-CoV-2, declarada pandemia por la Organización Mundial de la Salud el 11 de marzo del $2020^{1}$, y que tiene la capacidad de comprometer al sistema cardiovascular y producir afectación miocárdica, síndromes coronarios agudos, miocarditis, arritmias graves, tromboembolismo pulmonar agudo y pericarditis. Por otra parte, la pericarditis aguda es una inflamación de la membrana pericárdica que se debe casi siempre, en la mayor parte de los casos, a diversos virus cardiotropos $^{2}$. En este sentido, la relación entre ambas se ha descrito en escasa medida desde la aparición de este nuevo agente viral.

\section{Caso clínico}

Se presenta el caso de una paciente de 33 años, sin antecedentes de relevancia, que consultó por aparición de fiebre, astenia, anosmia, ageusia y tos seca de 72 horas de evolución. Se obtuvo hisopado nasal para realizar reacción en cadena de la polimerasa para COVID-19, que resultó positivo. Se solicitó tomografía computarizada de tórax que descartó alteraciones del parénquima pulmonar y derrames pleural o pericárdico. Estudios de laboratorio: hematócrito, 38\%; hemoglobina, $12 \mathrm{~g} / \mathrm{dl}$; leucocitos, 4,900 células/ $\mu$; plaquetas, 173,000/ul; y proteína C reactiva (PCR), $4.5 \mathrm{mg} / \mathrm{l}$. Al sexto día del inicio de los síntomas presentó dolor torácico punzante que empeoraba con la inspiración profunda y mejoraba con el cambio del decúbito. La exploración física reveló frote sistólico y diastólico en posición de plegaria mahometana. El electrocardiograma (ECG) demostró taquicardia sinusal a $100 \mathrm{lpm}$, bloqueo incompleto de rama derecha, segmento ST infradesnivelado de $0.5 \mathrm{mV}$ en DII, DIII, aVF, V5 y V6, y supradesnivelado cóncavo de $0.5 \mathrm{mV}$ en $\mathrm{V} 1$ y V2 con $\mathrm{T}$ concordante. El análisis de laboratorio registró el nivel de troponina $T$ ultrasensible $<14 \mathrm{ng} / \mathrm{l}$ y la creatinina fosfocinasa de $55 \mathrm{UI} / \mathrm{I}$ (VN 20/180), mientras que el resto de los parámetros fueron normales. El ecocardiograma transtorácico (ETT) mostró buena función biventricular con engrosamiento parietal sistólico conservado, marcada refringencia pericárdica posterior y ausencia de derrame pericárdico (Fig. 1A y 1B). Se interpretó el cuadro como pericarditis de probable causa viral por SARS-CoV-2, ya que se identificaron tres criterios diagnósticos de inflamación pericárdica en el contexto de dicha infección viral. Se inició ibuprofeno a dosis de 1,800 mg al día, con mejoría, y egresó del hospital a los siete días tras su ingreso.

La paciente buscó atención en los consultorios de cardiología a los cinco días de su egreso por persistencia del dolor torácico en forma subintrante a pesar del tratamiento antiinflamatorio. El ECG demostró
Correspondencia:

${ }^{*}$ Cristhian E. Scatularo

E-mail: emmanuelscatularo@ gmail.com
Fecha de recepción: 26-01-2021

Fecha de aceptación: 29-04-2021 DOI: 10.24875/ACM.21000033
Disponible en internet: 02-06-2021 Arch Cardiol Mex. 2021;91(Supl):140-142 www.archivoscardiologia.com CC BY-NC-ND (http://creativecommons.org/licenses/by-nc-nd/4.0/). 

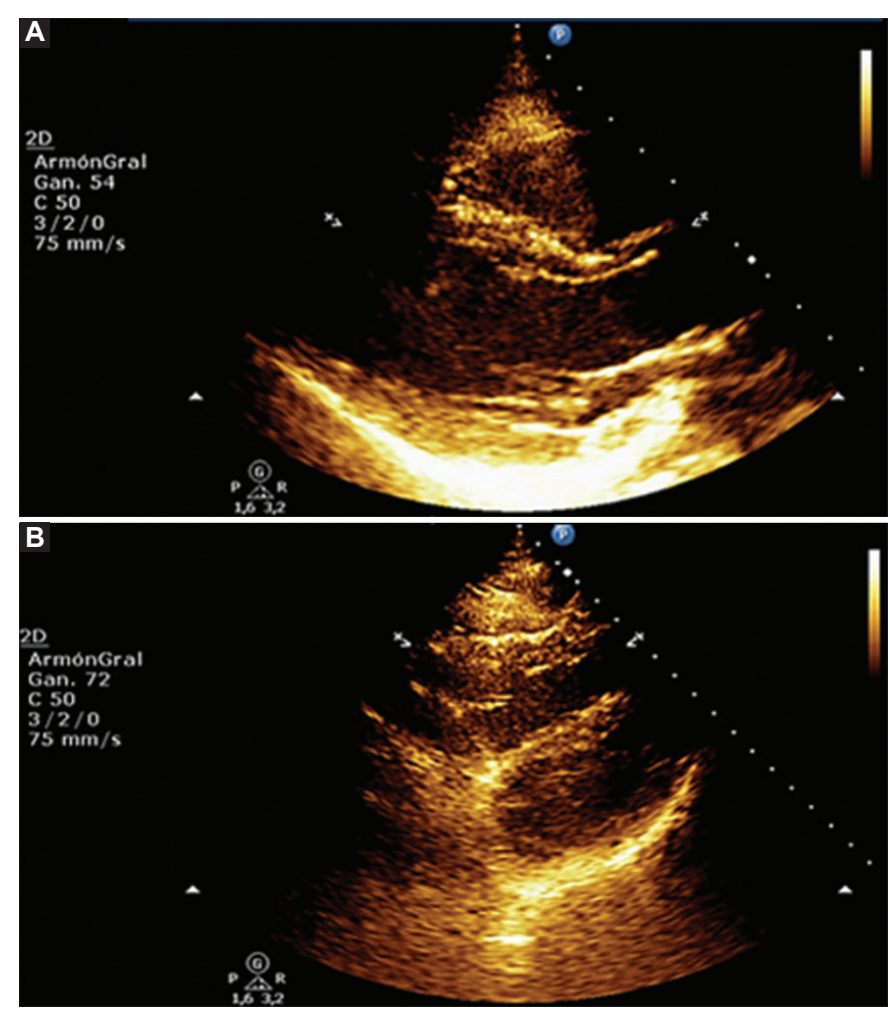

Figura 1. Ecocardiogramas transtorácicos. A: eje largo paraesternal en el que se observa una marcada refringencia del pericardio en la cara posterior. B: vista subcostal de cuatro cámaras, con refringencia pericárdica en la cara lateral del ventrículo izquierdo.

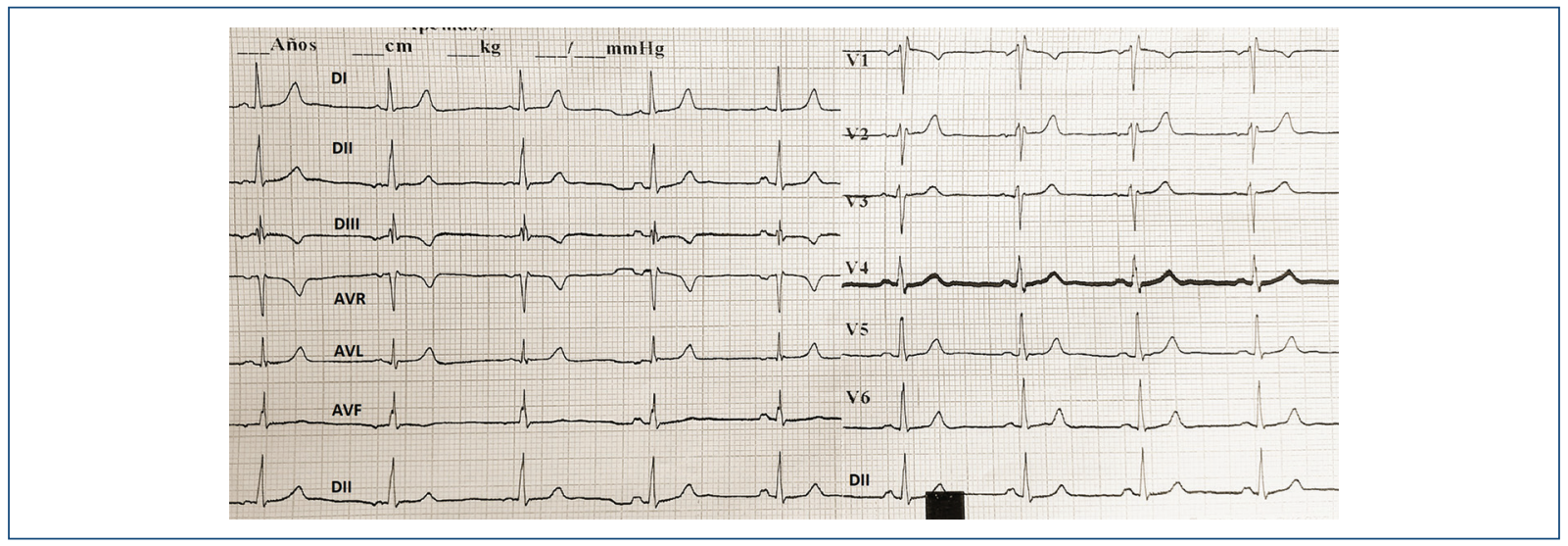

Figura 2. Electrocardiograma de control a los 23 días tras el inicio de los síntomas, sin cambios típicos de pericarditis evidentes.

normalización de los cambios iniciales, pero con alternancia de ritmo sinusal y auricular bajo asintomático (Fig. 2), la cifra de troponina resultó negativa y el ETT no señaló cambios con respecto al previo. Se agregó al tratamiento inicial colchicina a razón de
$0.5 \mathrm{mg}$ cada 12 horas. En el seguimiento a largo plazo se suspendió el ibuprofeno y cumplió tres meses de tratamiento con colchicina dada la evolución con mejoría de los síntomas, negativización de la PCR y ausencia de recurrencia. 


\section{Discusión}

La pericarditis aguda es un síndrome consecutivo a la inflamación pericárdica, con o sin derrame pericárdico adjunto, y sus causas más frecuentes son infecciones virales y las formas idiopáticas ${ }^{2}$. Su diagnóstico se establece si se satisfacen dos de cuatro criterios clínicos y siempre debe descartarse miocarditis adjunta mediante determinación de los marcadores de lesión miocárdica². Cabe destacar que el hallazgo en este caso de hiperrefringencia del pericardio posterior o lateral puede ser un dato inespecífico debido a la mayor distancia de estas estructuras al transductor del ETT, por lo que siempre es fundamental evaluar el pericardio mediante tomografía computarizada de tórax. El tratamiento inicial es la administración de antiinflamatorios no esteroideos y colchicina para reducir la inflamación y el dolor torácico y prevenir la recurrencia, en tanto que los corticoides se reservan ante contraindicación o falta de respuesta al tratamiento inicial ${ }^{2}$. Los factores relacionados con peor evolución incluyen fiebre, evolución subaguda, derrame pericárdico grave o taponamiento cardíaco, y la falta de respuesta a los antiinflamatorios en los primeros siete días².

Se han publicado múltiples casos de afectación cardiovascular en pacientes con COVID-19 y se calcula que entre $7 \%$ y $28 \%$ de los pacientes desarrollan compromiso miocárdico adjunto ${ }^{1,3}$. No obstante, la afectación pericárdica no parece ser tan frecuente como la miocárdica ${ }^{4-6}$.

\section{Conclusión}

Se presentó un caso de pericarditis aguda aislada de presentación típica secundaria a SARS-CoV-2. Es probable que tanto la pericarditis como otras anomalías cardiovasculares menores se subdiagnostiquen como consecuencia del menor número de consultas en emergencias en el marco del confinamiento obligatorio, por lo que resulta fundamental reforzar no sólo la consulta médica ante un dolor precordial, sino también la sospecha diagnóstica.

\section{Financiamiento}

Esta investigación no ha recibido ninguna beca específica de agencias de los sectores público, comercial, o sin ánimo de lucro.

\section{Conflicto de intereses}

Ninguno.

\section{Responsabilidades éticas}

Protección de personas y animales. Los autores declaran que para esta investigación no se han realizado experimentos en seres humanos ni en animales.

Confidencialidad de los datos. Los autores declaran que han seguido los protocolos de su centro de trabajo sobre la publicación de datos de pacientes.

Derecho a la privacidad y consentimiento informado. Los autores han obtenido el consentimiento informado de los pacientes o sujetos referidos en el artículo. Este documento obra en poder del autor de correspondencia.

\section{Bibliografía}

1. Atri D, Siddiqi HK, Lang J, Nauffal V, Morrow DA, Bohula EA. COVID-19 for the cardiologist: a current review of the virology, clinical epidemiology, cardiac and other clinical manifestations and potential therapeutic strategies. JACC: Basic to Translational Science. 2020 (Online). Doi:10.1016/j. jacbts.2020.04.002

2. Adler $Y$, Charron P, Imazio M, Badano L, Barón-Esquivias G, Bogaert J, et al. 2015 ESC Guidelines for the diagnosis and management of pericardial diseases: The Task Force for the Diagnosis and Management of Pericardial Diseases of the ESC. European Heart Journal. 2015;36(42):2921-64.

3. Wang D, Hu B, Hu C, Fangfang Z, Xing L, Jing Z, et al. Clinical characteristics of 138 hospitalized patients with 2019 novel coronavirus-infected pneumonia in Wuhan, China. JAMA. 2020;323(11):1061-69.

4. Tung-Chen Y. Acute pericarditis due to COVID-19 infection: an underdiagnosed disease? Med Clin. 2020 (Online). https://doi.org/10.1016/j. medcli.2020.04.007

5. Inciardi RM, Lupi L, Zaccone G, Italia L, Raffo M, Tomasoni D, et al. Cardiac involvement in a patient with coronavirus disease 2019. JAMA Cardiol. 2020;5(7):819-24.

6. Hua A, O'Gallagher K, Sado D, Byrne J. Life-threatening cardiac tamponade complicating myo-pericarditis in COVID-19. Eur Heart J. 2020;41(22):2130. 